\title{
Understanding advances in the simulation of intraseasonal variability in the ECMWF model. Part I: the representation of the MJO
}

Article

Published Version

Hirons, L. C., Inness, P., Vitart, F. and Bechtold, P. (2013) Understanding advances in the simulation of intraseasonal variability in the ECMWF model. Part I: the representation of the MJO. Quarterly Journal of the Royal Meteorological Society, 139 (675). pp. 1417-1426. ISSN 1477-870X doi: https://doi.org/10.1002/qj.2060 Available at https://centaur.reading.ac.uk/31398/

It is advisable to refer to the publisher's version if you intend to cite from the work. See Guidance on citing.

To link to this article DOI: http://dx.doi.org/10.1002/qj.2060

Publisher: Royal Meteorological Society

All outputs in CentAUR are protected by Intellectual Property Rights law, including copyright law. Copyright and IPR is retained by the creators or other copyright holders. Terms and conditions for use of this material are defined in the End User Agreement. 


\section{www.reading.ac.uk/centaur}

\section{CentAUR}

Central Archive at the University of Reading

Reading's research outputs online 


\title{
RMetS
}

Royal Meteorological Society

\section{Understanding advances in the simulation of intraseasonal variability in the ECMWF model. Part I: The representation of the MJO}

\author{
L. C. Hirons ${ }^{\star}$, P. Inness, F. Vitart and P. Bechtold \\ Department of Meteorology, University of Reading, UK \\ ${ }^{\star}$ Correspondence to: L. C. Hirons, Department of Meteorology, University of Reading, Earley Gate, PO Box 243, Reading \\ RG6 6BB, UK. Email: l.c.hirons@reading.ac.uk
}

As a major mode of intraseasonal variability, which interacts with weather and climate systems on a near-global scale, the Madden-Julian Oscillation (MJO) is a crucial source of predictability for numerical weather prediction (NWP) models. Despite its global significance and comprehensive investigation, improvements in the representation of the MJO in an NWP context remain elusive. However, recent modifications to the model physics in the ECMWF model led to advances in the representation of atmospheric variability and the unprecedented propagation of the MJO signal through the entire integration period.

In light of these recent advances, a set of hindcast experiments have been designed to assess the sensitivity of MJO simulation to the formulation of convection. Through the application of established MJO diagnostics, it is shown that the improvements in the representation of the $\mathrm{MJO}$ can be directly attributed to the modified convective parametrization. Furthermore, the improvements are attributed to the move from a moisture-convergent- to a relative-humidity-dependent formulation for organized deep entrainment. It is concluded that, in order to understand the physical mechanisms through which a relative-humidity-dependent formulation for entrainment led to an improved simulation of the MJO, a more process-based approach should be taken. The application of process-based diagnostics to the hindcast experiments presented here will be the focus of Part II of this study. Copyright (c) 2012 Royal Meteorological Society

\begin{abstract}
Key Words: numerical weather prediction; Madden-Julian Oscillation; convection
Received 9 May 2012; Revised 9 August 2012; Accepted 28 September 2012; Published online in Wiley Online Library

Citation: Hirons LC, Inness P, Vitart F, Bechtold P. 2012. Understanding advances in the simulation of intraseasonal variability in the ECMWF model. Part I: The representation of the MJO. Q. J. R. Meteorol. Soc. DOI:10.1002/qj.2060
\end{abstract}

\section{Introduction}

The Madden-Julian Oscillation (MJO; Madden and Julian, 1971) is the dominant mode of intraseasonal variability in the Tropics. It can be characterized as a planetaryscale convective anomaly with an associated overturning atmospheric circulation which propagates east from the Indian Ocean through the Maritime Continent into the West Pacific. An MJO event lasts between 30 and 60 days; however, the phenomenon has been shown to be highly episodic (Salby et al., 1994). For a detailed review of the structure and life cycle of the MJO see Zhang (2005).

Modelling the MJO challenges our understanding of convective processes in the tropical atmosphere because it encompasses multi-scale interactions (Nakazawa, 1988), ranging from the triggering of individual convective plumes on sub-grid scales to the organization and propagation of convection on a planetary scale. The MJO is an important 
source of predictability in its own right, but its interactions with other components of the climate system make it a necessary phenomenon for models to capture. The passage of the MJO through the equatorial Indo-Pacific has been shown to interact with the Asian (e.g. Lawrence and Webster, 2002) and Australian (e.g. Hendon and Liebmann, 1990) Summer Monsoon systems, as well as influence rainfall variability on a near-global scale (e.g. Bond and Vecchi, 2003; Matthews, 2004). Studies have also shown that the MJO modulates tropical cyclogenesis (e.g. Maloney and Hartmann, 2000; Mo, 2000) and can affect the strength and onset of the El Niño-Southern Oscillation (ENSO; Kessler and McPhaden, 1995). Despite its global importance in the climate system and extensive study in recent decades, deficiencies remain in our ability to model the phenomenon (e.g. Slingo et al., 1996; Lin et al., 2006).

This study examines the representation of the MJO in the Integrated Forecasting System (IFS) at the European Centre for Medium-Range Weather Forecasting (ECMWF), a state-of-the-art numerical weather prediction (NWP) model. Previously, the IFS exhibited a distinct loss of MJO amplitude in the early days of the forecast and had difficulty propagating the convective signal through the Maritime Continent (Vitart, 2003), a problem common to other models (e.g. Inness and Slingo, 2006). However, coupling the IFS to a mixed-layer ocean model (Woolnough et al., 2007) and modifying the model physics (Vitart et al., 2007) have been shown to improve the skill of MJO forecasts.

More recent modifications to the convection and vertical diffusion schemes in cycle 32r3 (Cy32r3) of the IFS led to significant advances in the simulation of atmospheric variability on intraseasonal time-scales; Cy32r3 was the first version of the IFS that was able to realistically sustain the amplitude of the MJO throughout the integration period (Bechtold et al., 2008; hereafter B08). While the B08 study showed clear advances in the simulation of intraseasonal variability, it could not identify which part of the modified physics was responsible for the observed advances or why they occurred. The aim of the current study is to extend the work of B08 to establish the role of individual aspects of the IFS modified physics in accurately simulating the MJO. The hindcast experiments designed to do so and the analysis techniques used for model evaluation are described in sections 2.1 and 2.2 respectively. The attribution of advances in MJO simulation to particular aspects of the Cy32r3 convection scheme is shown in section 3; discussion and conclusion follow in sections 4 and 5 respectively. Understanding the physical mechanisms through which these advances in MJO simulation were achieved are examined in Part II (Hirons et al., 2012.

\section{Methodology}

\subsection{Model description and experimental set-up}

The revisions to the convection scheme in Cy32r3 of the IFS (B08) included: (a) replacing the constant, resolutiondependent convective available potential energy (CAPE) adjustment time-scale $(\tau)$ in the closure for deep convection with a variable $\tau$, dependent on the updraught vertical velocity averaged over the cloud depth; and (b) changing the dependence of organized entrainment in the formulation for deep convection from a moisture-convergent-dependent formulation $\left(\epsilon_{\mathrm{org}}^{\mathrm{MC}}\right)$ to one dependent on the relative humidity of the surrounding environment $\left(\epsilon_{\mathrm{org}}^{\mathrm{RH}}\right)$. The motivation for the entrainment formulation change was twofold. First, changing the control on convection was aimed at removing known model errors. The previous $\epsilon_{\mathrm{org}}^{\mathrm{MC}}$ created a nonlinear feedback between convection and largescale dynamics that resulted in errors in precipitation and cloud-top height (B08). Second, changing to $\epsilon_{\mathrm{org}}^{\mathrm{RH}}$ addressed the emerging recognition in the literature that convective parametrizations in NWP models do not exhibit sufficient sensitivity to environmental humidity (e.g. Redelsperger et al., 2002; Derbyshire et al., 2004).

To understand the effects of different aspects of the modified convective parametrization a series of hindcast experiments, which differ only in their formulation of convection, have been performed during the Year of Tropical Convection (YOTC) period (Table 1). The hindcast experiments, initialized in May 2008, are compared to two control versions of the IFS (Cy31r1 and OPER). Cycle 31r1 (Cy31r1) is a version of the IFS prior to the convective modifications described above; it is the IFS version that was used to produce the ERA-Interim reanalysis dataset (Dee et al., 2011). The atmospheric component of the model is run at $T_{\mathrm{L}} 255$ resolution (about $80 \mathrm{~km}$ ) with 60 levels in the vertical, a model top at $0.1 \mathrm{hPa}$ and model time step of $30 \mathrm{~min}$. The integrations are initialized using ERAInterim reanalysis and forced daily by persisted sea-surface temperatures (SSTs) from the NCEP high-resolution, realtime, global (RTG) SST reanalysis until January 2009 and the National Centre for Ocean Forecasting (NCOF) Operational Sea Surface Temperature and Sea Ice Analysis (OSTIA) after January 2009. Cy31r1 uses the old radiation scheme, before the introduction of the McRad scheme (Morcrette et al., 2007). The convection scheme in Cy31r1 (prior to the modifications of B08) uses $\epsilon_{\mathrm{org}}^{\mathrm{MC}}$ and a constant, resolutiondependent $\tau$ (at $T_{\mathrm{L}} 255, \tau=3600 \mathrm{~s}$ ).

OPER refers to the evolving operational IFS cycle during the YOTC period, which all include the B08 modifications. The atmospheric resolution is $T_{\mathrm{L}} 799$ (about $25 \mathrm{~km}$ ) with 91 levels in the vertical, a model top at $0.01 \mathrm{hPa}$ and model time step of $12 \mathrm{~min}$. The integrations are initialized using the YOTC operational analysis and forced by persisted SST anomalies from NCEP RTG prior to October 2008 and from OSTIA after October 2008. The persisted SST anomalies are calculated by persisting the initial SST anomalies from the climatological seasonal cycle through the forecast, with the seasonal cycle continuing to evolve throughout the integration. The new McRad radiation scheme is used throughout OPER. The convection scheme in OPER uses $\epsilon_{\mathrm{org}}^{\mathrm{RH}}$ and a variable $\tau$ (at $T_{\mathrm{L}} 799,720<\tau<10800 \mathrm{~s}$ ).

All the hindcast experiments (CONV, ENTRN and CAPE) were performed using a version of the IFS which included the modified convective parametrization and the McRad radiation scheme. The horizontal resolution and initialization of the hindcast experiments are identical to OPER. Although ocean-atmosphere coupling has been shown to improve the simulation of the MJO, the effect of coupling only becomes important beyond a 10-day forecast lead time (Woolnough et al., 2007). For this reason, and to be consistent with the OPER control, the experiments are forced by persisted SST anomalies.

In CONV the convection scheme is reverted back to the pre-modified scheme; it uses $\epsilon_{\mathrm{org}}^{\mathrm{MC}}$ and a constant $\tau$. The convection scheme in CAPE uses a constant $\tau$ and $\epsilon_{\mathrm{org}}^{\mathrm{RH}}$. The convection scheme in ENTRN uses a variable $\tau$ 
Table 1. Summary of control IFS versions (Cy31rl and OPER) and hindcast experiments (CONV, ENTRN and OPER). YOTC (Year of Tropical Convection) refers to a period, from May 2008 to January 2010, of targeted observations, modelling and forecasting activities coordinated by the World Climate and Weather Research Programs (WCRP and WWRP).

\begin{tabular}{|c|c|c|c|c|c|c|}
\hline Control IFS experiments & Integration period & Analysis & Resolution & Radiation & Convection $\tau, \epsilon_{\text {org }}$ & Cycle \\
\hline Сy31r1 & YOTC period & ERA-Interim & $T_{\mathrm{L}} 255 \mathrm{~L} 60$ & 'Old' & $3600 \mathrm{~s}, \epsilon_{\mathrm{org}}^{\mathrm{MC}}$ & Cy31r1 \\
\hline OPER & YOTC period & Operational & $T_{\mathrm{L}} 799 \mathrm{~L} 91$ & McRad & $720-10800 \mathrm{~s}, \epsilon_{\mathrm{org}}^{\mathrm{RH}}$ & Cy32r3-Cy35r3 \\
\hline CONV & 05/2008-07/2009 & Operational & $T_{\mathrm{L}} 799 \mathrm{~L} 91$ & McRad & $720 \mathrm{~s}, \epsilon_{\mathrm{org}}^{\mathrm{MC}}$ & Cy33r1 \\
\hline ENTRN & 05/2008-07/2009 & Operational & $\mathrm{T}_{\mathrm{L}}$ 799L91 & McRad & $720-10800 \mathrm{~s}, 0.5 * \epsilon_{\mathrm{org}}^{\mathrm{RH}}$ & Cy33r1 \\
\hline CAPE & 05/2008-04/2009 & Operational & $T_{\mathrm{L}} 799 \mathrm{~L} 91$ & McRad & $720 s, \epsilon_{\mathrm{org}}^{\mathrm{RH}}$ & Cy33r1 \\
\hline
\end{tabular}

Table 2. Summary of IFS comparisons which isolate the effects of individual modifications to the convective parametrization.

\begin{tabular}{ll}
\hline Convection modification & IFS comparison \\
\hline Cy32r3 $\left(\epsilon_{\text {org }}^{\mathrm{RH}} \& \tau\right)$ & OPER-CONV \\
$\epsilon_{\mathrm{org}}$ formulation & CAPE-CONV \\
$\tau$ & OPER-CAPE \\
$\epsilon_{\mathrm{org}}^{\mathrm{RH}}$ rate & OPER-ENTRN \\
\hline
\end{tabular}

and $0.5 * \epsilon_{\mathrm{org}}^{\mathrm{RH}}$ (see Table 1 for a summary). Halving the relative-humidity-dependent term in the formulation for entrainment amounts to approximately a $25 \%$ reduction in the overall entrainment. Table 2 indicates which individual convection modifications are highlighted by comparisons between versions of the IFS described in Table 1; for example, comparing CAPE and CONV isolates the effect of the $\epsilon_{\mathrm{org}}^{\mathrm{RH}}$ formulation.

\subsection{Observational data}

Daily outgoing long-wave radiation (OLR) data are obtained from the National Oceanic and Atmospheric Administration (NOAA) Earth System Research Laboratory (ESRL). Readings from the Advanced Very High Resolution Radiometer (AVHRR) satellite are interpolated onto a global $2.5^{\circ} \times 2.5^{\circ}$ grid following Liebmann and Smith (1996). Comparisons are also made with ERA-Interim reanalysis data (Dee et al., 2011), which are constructed using Cy31r1, as described in section 2.1.

\subsection{Analysis technique}

Many of the analysis techniques applied in this study are consistent with those of Waliser et al. (2009) as recognition of efforts in the modelling community to define a validation framework for assessing the simulation of the MJO. One such diagnostic is single-field wavenumber-frequency spectra for equatorially averaged $\left(10^{\circ} \mathrm{N}-10^{\circ} \mathrm{S}\right)$ OLR (section 3.3) and $850 \mathrm{hPa}$ zonal wind (not shown). The spectra are calculated by applying a Fourier transformation to a 365day time series (from May 2008 to April 2009) and forming power, resulting in a bandwidth of $(365)^{-1}$. By construction, positive wavenumbers and frequencies represent eastward propagation. For westward propagation to be identified, either the wavenumber or frequency must be negative. If there is equal power in the eastward and westward directions, then a standing oscillation is present.

A further diagnostic advocated by Waliser et al. (2009) and widely used to analyse MJO activity through the YOTC period is the real-time, multivariate MJO index (Wheeler and Hendon, 2004). The index is based on the first two combined empirical orthogonal functions (EOFs) of nearequatorially averaged OLR, and zonal winds at $850 \mathrm{hPa}$ and $200 \mathrm{hPa}$, which together account for approximately $25 \%$ of the total variance. The positive and negative phases of EOF1 describe active and suppressed convection over the Maritime Continent region respectively. The positive (negative) phase of EOF2 describes active (suppressed) convection over the West Pacific and suppressed (active) convection over the Indian Ocean. The projection of the daily model data, with components of seasonal and interannual variability removed, onto the two combined EOFs produces two principal component Real-time Multivariate MJO (RMM) time series, RMM1 and RMM2. The indices effectively isolate MJO variability and, plotted in RMM phase space, indicate the propagation characteristics of individual events. The MJO amplitude is defined from the index as $\sqrt{\mathrm{RMM1}^{2}+\mathrm{RMM}^{2}}$. During April 2009 a strong MJO event is identified; this case study is analysed using the multivariate MJO index. In this analysis, the same observed EOFs, which are pre-calculated from NCEP reanalysis, are used for observations and simulations (section 3.4).

\section{Results}

\subsection{Control IFS versions}

The initial comparison between the control IFS versions, Cy31r1 and OPER, will indicate the progress in simulating MJO activity in the IFS since 2006. Intraseasonal OLR (Figure 1) and $850 \mathrm{hPa}$ zonal wind (Figure 2) anomalies are extracted using a 20- to 100-day bandpass filter. The integration period of the hindcast experiments is not long enough to apply the same filter. At a 1-day forecast lead time both Cy31r1 and OPER exhibit coherent eastwardpropagating dynamical (Figure 2(b) and (c)) and convective (Figure 1(b) and (c)) signals on intraseasonal time-scales, which agree well with observations.

At a 10-day forecast lead time the amplitude of the intraseasonal OLR variance and the associated zonal wind anomalies in Cy31r1 have weakened considerably and the anomalies which do develop do not exhibit coherent eastward propagation (Figures 1 and 2(d)). Conversely, in OPER increasing forecast lead time strengthens the convective anomalies, although they still exhibit a less coherent propagating structure compared with observations (Figure 1(e)). At this lead time, OPER is particularly overactive in the Western Hemisphere; the convective anomalies which form between $60^{\circ} \mathrm{W}$ and $30^{\circ} \mathrm{W}$ are stronger than those observed by satellite. In OPER the propagation and amplitude of the westerly and easterly wind 


\section{C. Hirons et al.}

(a) AVHRR satellite

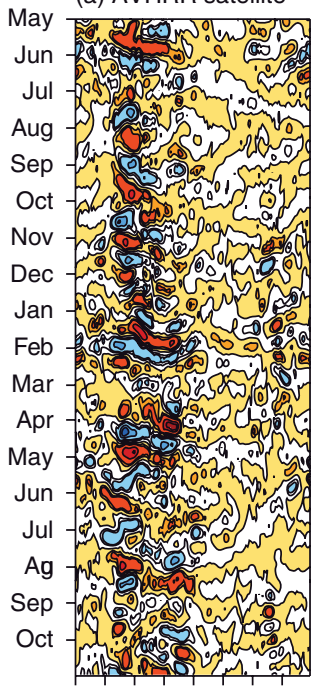

o 90E 180 90W

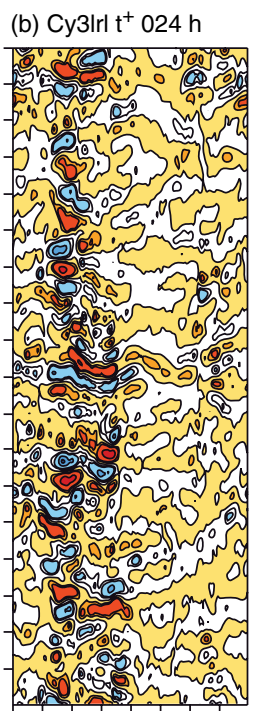

o 90E 180 90W

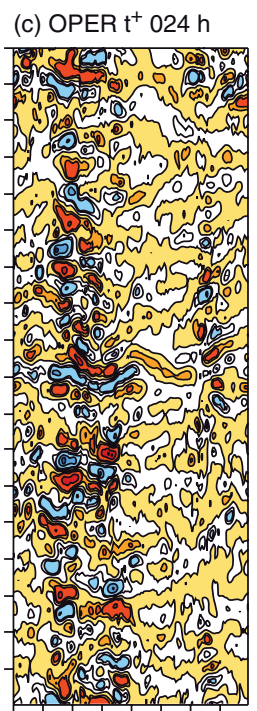

0 90E 180 90W

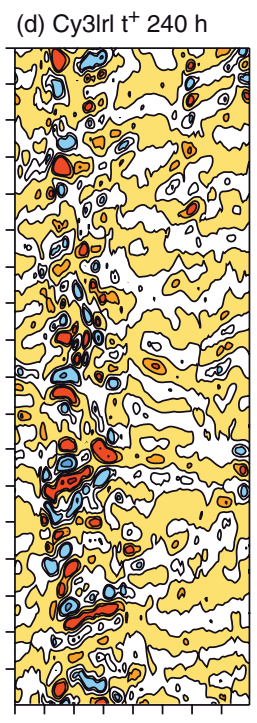

o 90E 180 90W

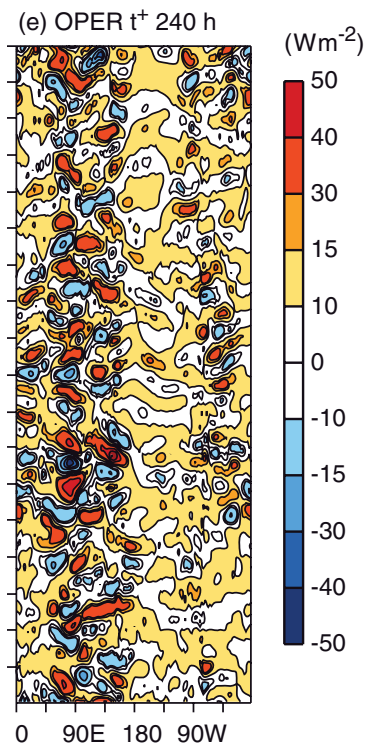

Figure 1. Hövmuller (time-longitude) diagrams of 20- to 100 -day band-pass-filtered OLR averaged between $10^{\circ} \mathrm{N}$ and $10^{\circ} \mathrm{S}$, May 2008 to October 2009: (a) NOAA AVHRR satellite data; (b, d) Cy31r1 verified at 1- and 10-day forecast lead time, respectively. (c, e) OPER verified at 1- and 10-day forecast lead time, respectively.

(a) ERA-Interim reanalysis $\quad$ (b) Cy3lrl t ${ }^{+} 024 \mathrm{~h}$

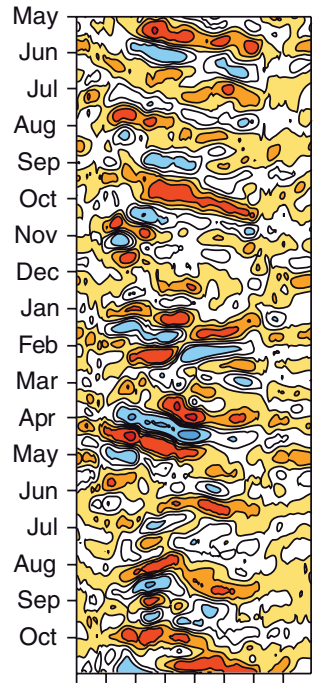

$0 \quad 90 \mathrm{E} 180$ 90W

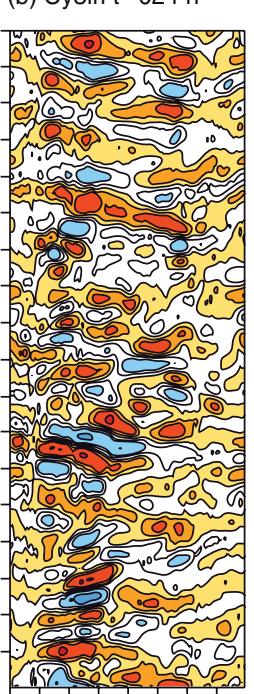

0 90E 180 90W (c) OPER t+ $024 \mathrm{~h}$

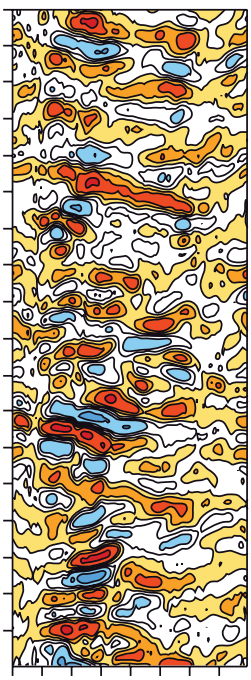

0 90E 180 90W (d) Cy3lrl t+ $240 \mathrm{~h}$

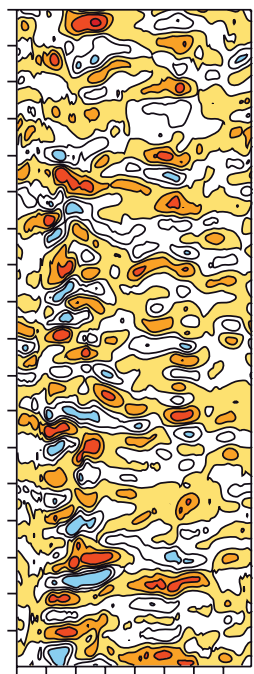

0 90E 180 90W (e) OPER $\mathrm{t}^{+} 240 \mathrm{~h}$

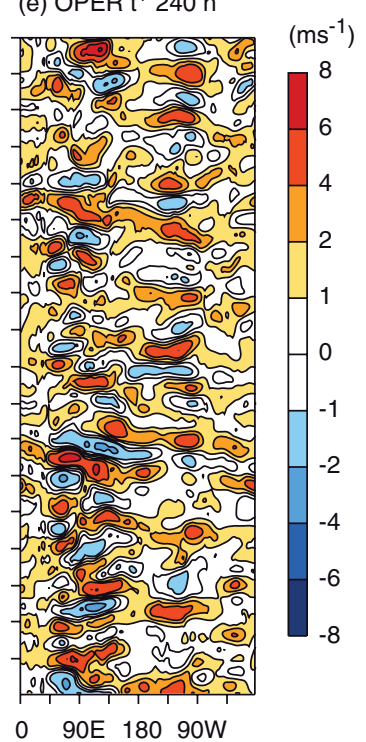

Figure 2. As Figure 1, but for $850 \mathrm{hPa}$ zonal wind compared with (a) ERA-Interim reanalysis.

anomalies associated with the MJO more closely follow the analysis than in Cy31r1 (Figure 2(d) and (e)); this will be discussed further in section 4.1.

While this 'old-model, new-model' comparison highlights improvements in the representation of the MJO, the model configurations differ considerably (Table 1); therefore, it cannot attribute those advances to specific model changes. It is only through comparisons with the hindcast experiments that the effect of individual model modifications can be extracted (Table 2).

\subsection{Variance of $O L R$}

Figure 3 shows the unfiltered OLR variance in the Tropics from AVHRR satellite data, the IFS control versions Cy31r1 and OPER, and the hindcast experiments CONV, ENTRN and CAPE, at a 5-day forecast lead time (Figure 3(a)). The satellite data exhibit a similar spatial pattern in the variance of unfiltered OLR compared with the intraseasonally filtered equivalent (not shown). The largest variance of OLR is located over the equatorial Indian Ocean, Bay of Bengal and West Pacific Warm Pool, extending south of the Equator through the Australian monsoon region into the South Pacific convergence zone (SPCZ); there is little variance in daily OLR along the equatorial eastern Pacific. The larger Indonesian islands exhibit a local minimum in variance.

At a 5-day forecast lead time, the longest lead time at which the comparisons between the hindcast experiments can be made, all versions of the IFS reproduce the spatial pattern of variance in daily OLR with reasonable accuracy. However, discrepancies are evident in the magnitude of convective variability. Comparing OPER and CONV (CAPE and CONV) with the satellite data indicates that the introduction of the Cy32r3 convection scheme $\left(\epsilon_{\mathrm{org}}^{\mathrm{RH}}\right)$ 
(a) NOAA AVHRR satellite

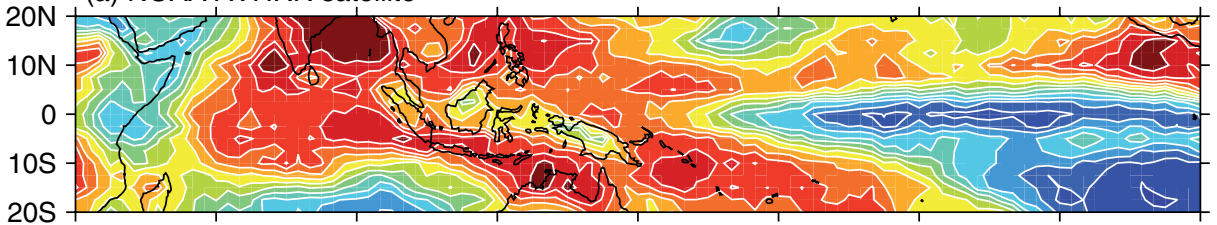

(b) Cy31r1

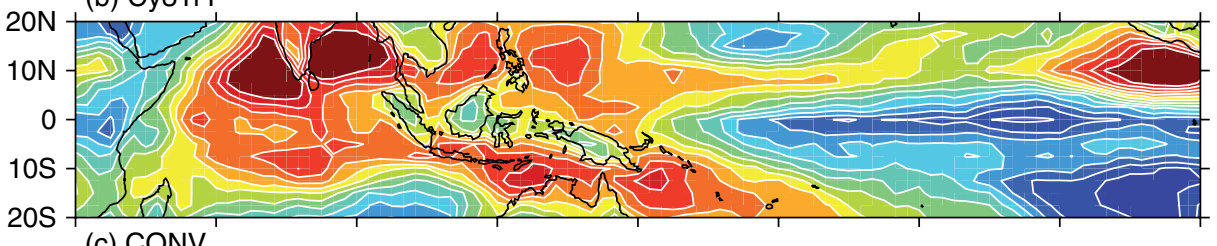

(c) CONV
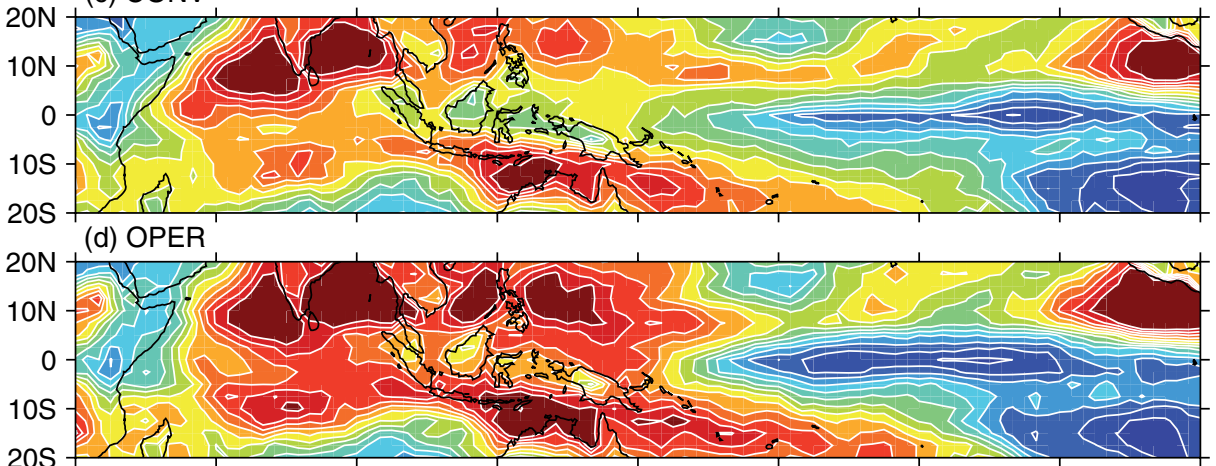

(e) ENTRN

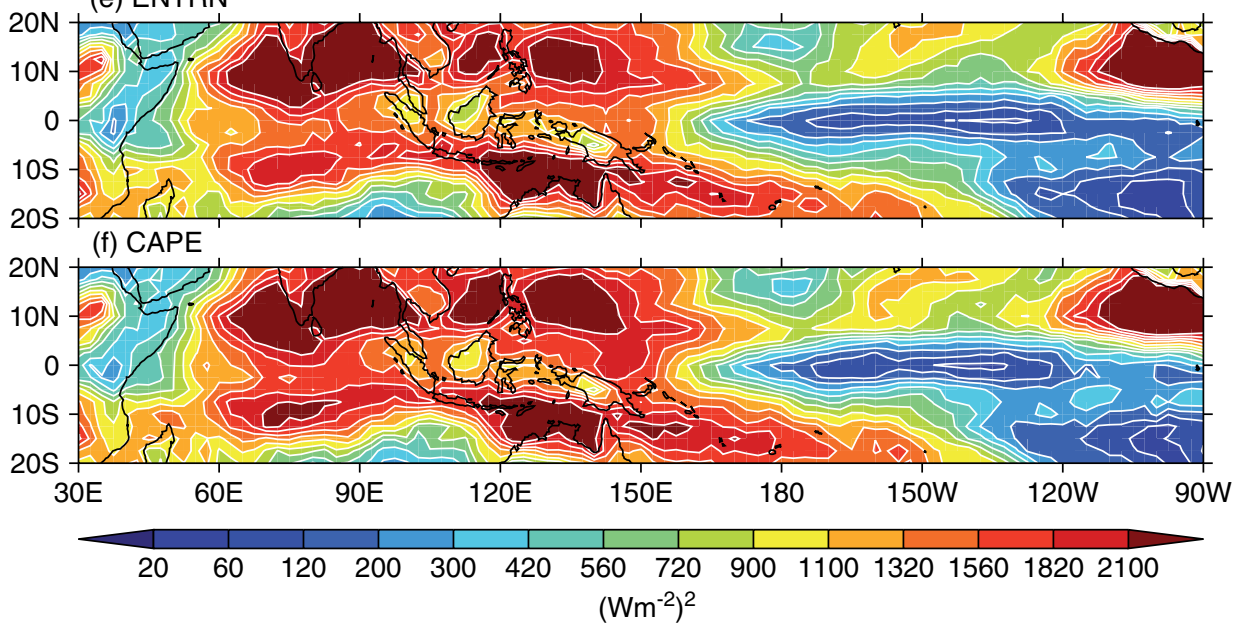

Figure 3. Variance of unfiltered OLR for May 2008 to April 2009 from: (a) NOAA AVHRR satellite data and Cy31r1, CONV, OPER, ENTRN and CAPE; $(\mathrm{b}-\mathrm{f})$ at 5 -day forecast lead time.

increased the magnitude of convective variability in the entire Indo-Pacific region (Figure 3(a), (b), (d) and (f)). However, OPER overestimates the magnitude of convective variability north of the Equator in the South China and Philippine seas as well as in the eastern Pacific, while south of the Equator the most prominent increases are in the Indian Ocean and Australian monsoon region. The local reduction in convective variability over the Indonesian islands is less well defined with the introduction of the Cy32r3 convection scheme (Figure 3(a), (c) and (d)). Both CONV and Cy31r1 underestimate the magnitude of OLR variance in the entire Indo-Pacific region. This suggests that the other, nonconvection scheme changes between Cy31r1 and OPER, such as increased horizontal and vertical resolution, and the introduction of McRad, the new radiation scheme, had little effect on the simulation of OLR variance in the Tropics (Figures 3(a)-(c)). Additionally, the spatial distributions and magnitudes of convective variability in CAPE, ENTRN and OPER are similar to each other and distinct from Cy31r1 and CONV. This suggests that the relative-humiditydependent entrainment formulation, used in CAPE, ENTRN and OPER, and not used in Cy31r1 or CONV, is the more dominant of the two modifications to the convective parametrization scheme. Comparing ENTRN and OPER suggests that a possible effect of halving the rate of $\epsilon_{\mathrm{org}}^{\mathrm{RH}}$, or reducing total entrainment by approximately $25 \%$, is that the representation of the minimum in OLR variance over the Indonesian islands is slightly improved. However, compared with observations, there is still too much variability over the islands. The introduction of the new variable CAPE adjustment time-scale $(\tau)$ has little impact on the variance in OLR.

As forecast lead time continues to increase, OLR variance continues to increase, resulting in an overestimation throughout the Indian Ocean in OPER. After 10 days of the forecast, CONV overestimates the amount of 
(a) NOAA AVHRR satellite

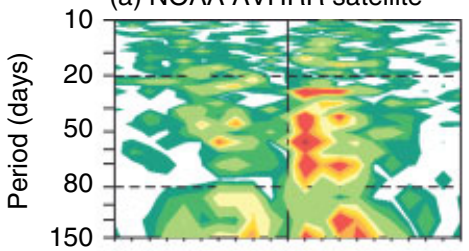

(b) Cy3lrl t $t^{+} 120 \mathrm{~h}$

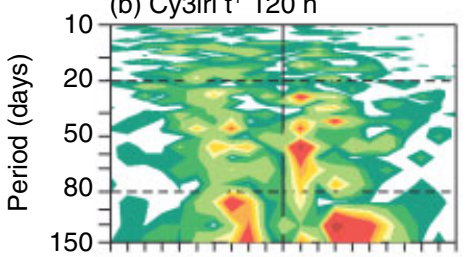

(d) CONV t $120 \mathrm{~h}$

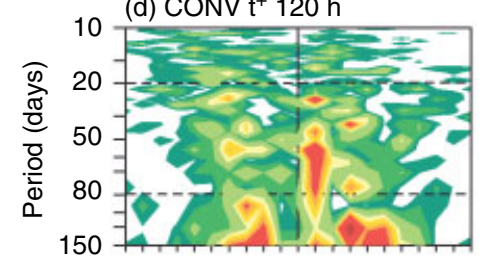

(f) OPER $\mathrm{t}^{+} 120 \mathrm{~h}$

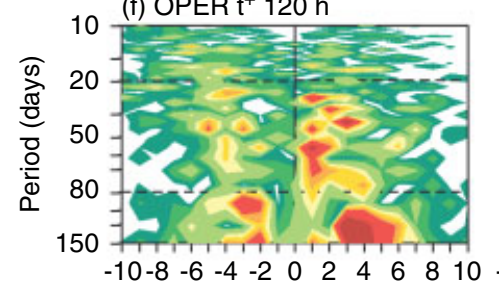

Zonal wavenumber (c) Cy3lrl t $240 \mathrm{~h}$

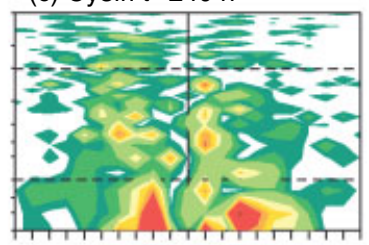

(e) CONV t $240 \mathrm{~h}$

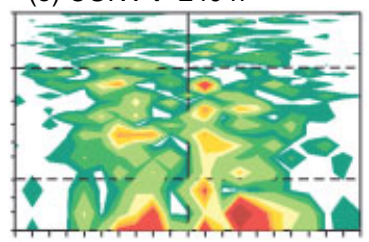

(g) OPER t $240 \mathrm{~h}$

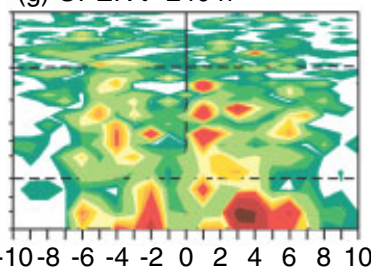

Zonal wavenumber

\begin{tabular}{llllllll}
\hline 0.06 & 0.12 & $\begin{array}{c}0.24 \\
\text { Spectral power in olr }\end{array}$ & 0.36 & 0.48 & 0.60 & 1.20 & 2.40 \\
& &
\end{tabular}

Figure 4. Space-time power spectra in equatorially averaged $\left(10^{\circ} \mathrm{N}-10^{\circ} \mathrm{S}\right)$ OLR for: (a) NOAA AVHRR satellite data; (b-g) Cy31r1, CONV and OPER at 5- and 10-day forecast lead time. Eastward and westward propagation are represented by the right- and left-hand side of the diagrams, respectively. Horizontal dashed lines have been added at 20 and 80 days to highlight the typical period of the MJO.

convective variability in the Arabian Sea and Bay of Bengal, and underestimates the variability in the equatorial Indian Ocean, South China and Philippine Seas, Australian monsoon region and SPCZ (not shown).

It is interesting to note, however, that the largest differences in Figure 3 occur in the Monsoon regimes poleward of the $10^{\circ} \mathrm{MJO}$ domain used in Figures 1 and 2. The revised convective parametrization was shown to increase convective variance generally (B08), not just in MJO-affected regions and frequencies. Therefore, this signature model bias, characterized by increases in OLR variance in southeast Asia, the west Pacific and east of the Philippines, is likely to be due to an overestimation of the convective moistening tendency and will be discussed further in Part II of this study.

\subsection{Space-time power spectrum}

Single-field wavenumber-frequency spectra (section 2.3) are calculated for all the versions of the IFS and compared with observations. The satellite-derived AVHRR OLR (Figure 4) exhibit a concentration of power at 20- to 80-day periods and eastward-propagating zonal wavenumber 1-3, consistent with the intraseasonal frequency and propagation characteristics of the MJO. At 20- to 80-day periods the eastward power in OLR is approximately five times the westward power. Both eastward and westward power are evident at longer periods in the OLR, indicating less coherent, lower-frequency propagating features. At a 1day forecast lead time, all versions of the IFS exhibit a concentration of power at 20- to 80-day periods and zonal wavenumber 1 , although the modelled power is weaker than observed.

At a 5-day forecast lead time there is a consistent overestimation, compared with observations, of power in low-frequency westward- and eastward-propagating wavenumbers. The impact of the Cy32r3 convection scheme at a 5-day forecast lead time (Figure 4(d) and (f)) is to increase the power in low-frequency eastwardpropagating wavenumbers, and slightly increase the power in the MJO signal and intraseasonal westward-propagating wavenumbers. $\epsilon_{\text {org }}^{\mathrm{RH}}$ is responsible for these changes but the variable $\tau$ has little effect. The simulation of MJO power is not sensitive to the rate of $\epsilon_{\mathrm{org}}^{\mathrm{RH}}$. At a 10 day forecast lead time, models with the pre-Cy32r3 convection scheme (Cy31r1 and CONV) exhibit a distinct weakening of the power in the intraseasonal frequencies associated with the MJO. The Cy32r3 convection scheme (OPER) is able to maintain the power of the eastwardpropagating intraseasonal frequencies at a 10-day forecast lead time, although the power of the westward-propagating intraseasonal frequencies also increases, and is stronger than 
(a)

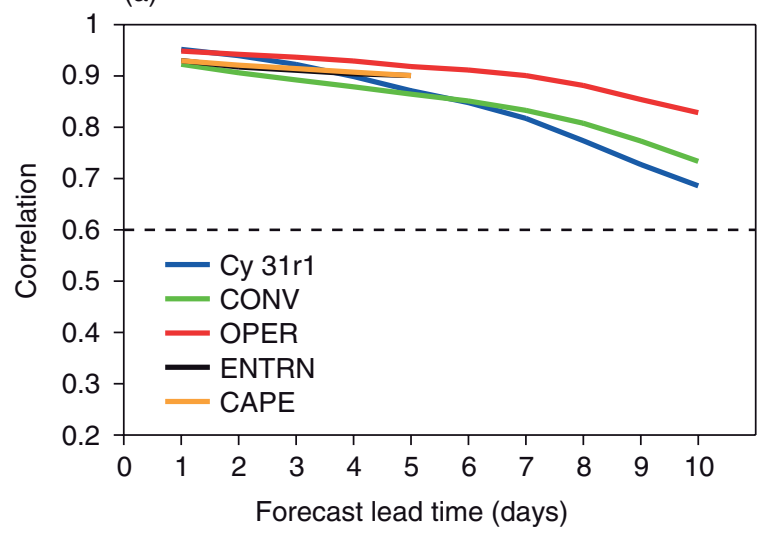

(b)

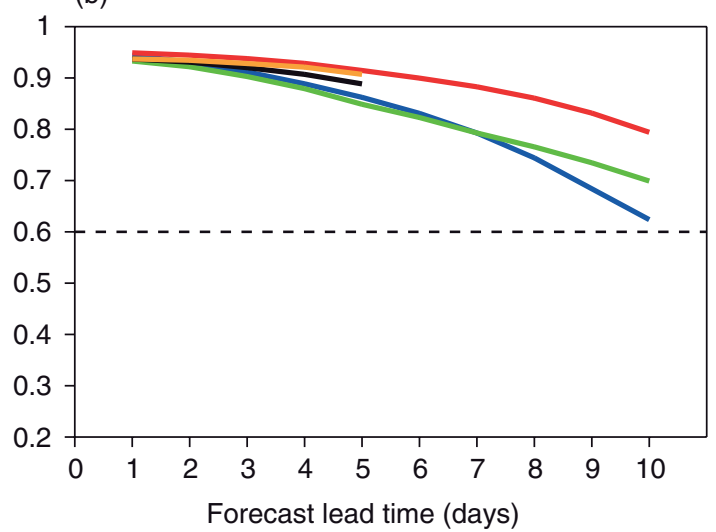

Figure 5. Linear correlations between observed and forecast (a) RMM1 and (b) RMM2 as a function of forecast lead time for the period from May 2008 to April 2009. The CAPE and ENTRN hindcast experiments do not extend to a 10-day forecast lead time.

observed (Figure $4(\mathrm{~g})$ ). Results are similar for $850 \mathrm{hPa}$ zonal wind (not shown). Therefore, using space-time power spectrum analysis it has been shown that $\epsilon_{\mathrm{org}}^{\mathrm{RH}}$ in the Cy32r3 convection scheme is responsible for maintaining the eastward-propagating intraseasonal power signal in OLR (Figure 4) and $850 \mathrm{hPa}$ wind (not shown) associated with the MJO at longer forecast lead times.

\subsection{Multivariate $\mathrm{MJO}$ index}

The multivariate MJO index (section 2.3) is used to evaluate the overall skill of the IFS in predicting the onset and evolution of the MJO. Linear correlations are performed between the time series of observed RMM1 and RMM2 and those produced from the IFS at each forecast lead time. A forecast is typically considered as skilful if the correlation exceeds 0.6 (e.g. Vitart and Molteni 2010); therefore, this threshold has been included in the diagrams.

According to Figure 5(a) and (b), at a 5-day forecast lead time ENTRN and CAPE exhibit similar levels of skill as OPER in predicting RMM1 and RMM2. Cy31r1, CONV and OPER all have skill (correlation $>0.6$ ) in predicting RMM1 and RMM2 at a 10-day forecast lead time. At the longer lead times, the IFS exhibits more skill in predicting RMM1, when the enhanced convective anomaly enters the Maritime Continent, than RMM2, when the enhanced convective anomaly is in the central Pacific. This is consistent with previous studies which have shown that the IFS has difficulty propagating the enhanced convection associated with the MJO through the Maritime Continent (e.g. Inness and Slingo, 2006; Vitart and Molteni, 2010). Although slight improvements in skill are apparent between Cy31r1 and CONV at longer forecast lead times, comparing CONV and OPER shows that large improvements in skill can be directly attributed to the Cy32r3 convection scheme. Skilful prediction of the MJO amplitude (MJO amplitude $\geq 1$ ) is increased by 4 (2) days with the introduction of the Cy32r3 convection scheme.

The diagnostics shown so far have described MJO activity through the YOTC period. One advantage of using an NWP approach to analyse MJO simulations is that individual MJO case studies can be analysed and compared with observations. The multivariate MJO index is used to analyse the April 2009 case study (Figure 6). The strong amplitude and eastward propagation are clear in both the observations (black line) and ERA-Interim reanalysis (dark red line). At the start of April, as the enhanced convection associated with the MJO entered the Indian Ocean, it already had a large amplitude. The amplitude remained large as, during April, the MJO signal propagated across the Indian Ocean, through the Maritime Continent and into the West Pacific. As forecast lead time increases, there is a distinct loss of MJO amplitude in the pre-Cy32r3 convection scheme cycles of the IFS (Cy31r1, CONV; Figure 6(a) and (b)). At longer forecast lead times, the effect of $\epsilon_{\text {org }}^{\mathrm{RH}}$ (comparing CONV with CAPE) is to increase the amplitude of the MJO. The most prominent increase in MJO amplitude is in the Indian Ocean, resulting in a large overestimation compared with observations. The increase in MJO amplitude results in an underestimation of MJO activity, which is relatively small in the Maritime Continent but much larger in the West Pacific. The main effect of the variable $\tau$ (comparing CAPE with OPER) is to reduce the amplitude of the MJO in the Indian Ocean; there is little impact in other regions. The compensating effects of $\epsilon_{\mathrm{org}}^{\mathrm{RH}}$ and $\tau$ which increase and decrease the amplitude of the MJO in the Indian Ocean respectively, mean that at longer forecast lead times the Cy32r3 convection scheme (comparing CONV with OPER) maintains the observed magnitude of MJO amplitude in that region. However, at longer forecast lead times, in the Maritime Continent and especially in the West Pacific, the Cy32r3 convection scheme exhibits less skill than in the Indian Ocean in predicting the evolution of the April 2009 MJO.

\section{Discussion of results}

\subsection{Convective versus dynamical signal of the MJO}

While Cy31r1 loses the coherent MJO signals in the OLR and wind field after a few days lead time, OPER is able to maintain these structures throughout the 10-day forecast period (section 3.1). However, the variance in OPER increases with forecast lead time, which is due to a moistening tendency and will be examined in further detail in Part II of this study. The large-scale dynamical signal of the MJO (Figure 2) is better preserved at a 10-day forecast lead time in OPER than the associated convective signal (Figure 1). The convective and large-scale circulation signals associated with the MJO are widely considered to be strongly coupled; however, this result implies that there is a lack of coherence between the convective heating and the large-scale wave forcing in the IFS 
(a) Cy31r1

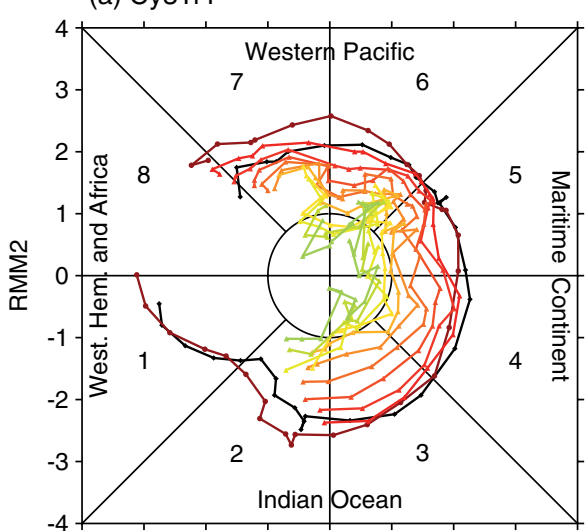

(d) ENTRN (b) CONV

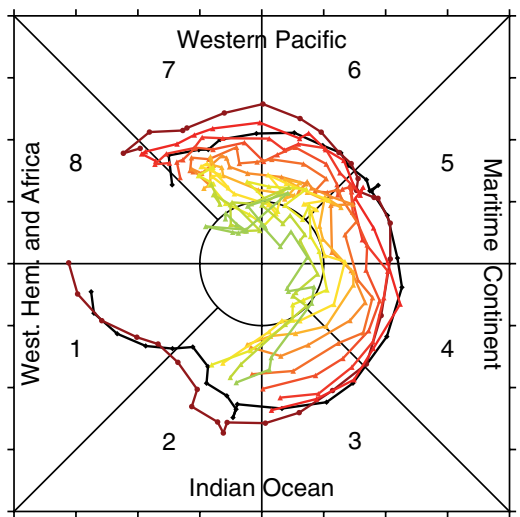

(e) CAPE
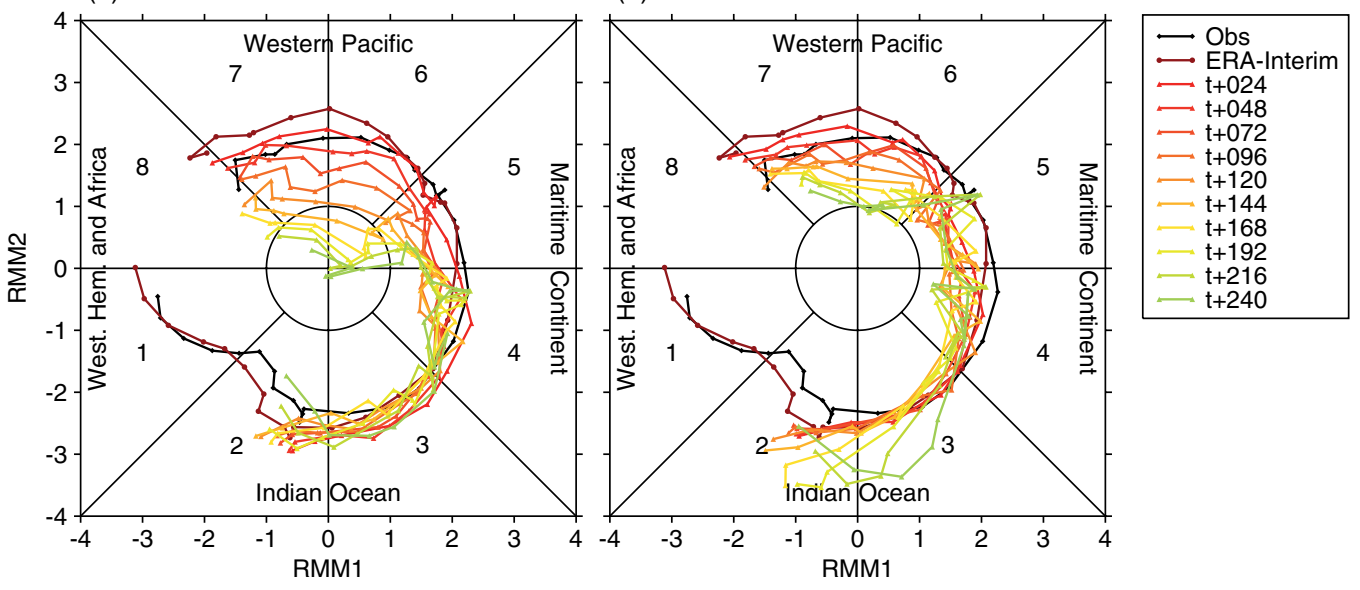

(c) OPER

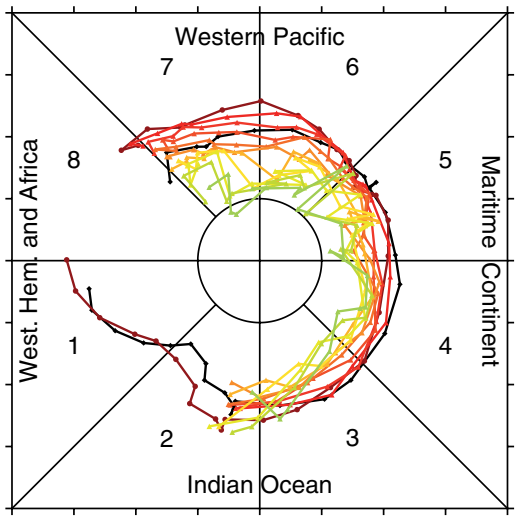

Figure 6. Multivariate MJO index for the April 2009 case study from observations (black line), ERA-Interim reanalysis (dark red line) and versions of the IFS plotted on forecast validation date at increasing forecast lead time from 1 day (red line) to 5 days (light orange line). Observations refer to RMM1 and RMM2 calculated using satellite-derived OLR and NCEP reanalysis zonal winds at $850 \mathrm{hPa}$ and $200 \mathrm{hPa}$.

as forecast lead time increases. This characteristic of the IFS prompts the question of whether the model is producing an MJO-like signal for the wrong reasons. Interestingly, this is not a feature exclusive to the IFS, but is consistent with other studies. Comparing four pairs of coupled and uncoupled global simulations, Zhang et al. (2006) showed that the precipitation signal associated with the MJO was much weaker than observed, while the dynamical signal in the zonal winds was stronger than observed. Kim et al.(2009) showed that, while the variability of precipitation and zonal wind were spatially correlated, many models underestimated the intraseasonal spectral power of both. However, in general, the large-scale dynamical signal of the MJO was better represented than the convective signal in many models.

\subsection{Reduction of eastward-propagating spectral power}

The advances in MJO simulation can be summarized using a metric derived from the wavenumber-frequency spectra discussed in section 3.3. Figure 7 shows the east-west ratio of MJO spectral power, defined as the 20- to 80day mode within wavenumbers $1-3$ for OLR and 1-2 for $850 \mathrm{hPa}$ zonal wind. In observations (AVHRR OLR and ERA-Interim $850 \mathrm{hPa}$ zonal wind), the east-west power is 3-4 for OLR and 4-5 for zonal wind. Since the forecasts are initiated from ERA reanalysis, unsurprisingly all versions of the IFS exhibit equivalent east-west ratios of zonal wind to ERA-Interim (4-5). The forecast east-west ratios of OLR, however, are significantly reduced (2-3) compared with observations (3-4). As forecast lead time increases, versions of the IFS with $\epsilon_{\mathrm{org}}^{\mathrm{RH}}$ (OPER, CAPE and ENTRN; red, orange and black lines) maintain a higher east-west ratio than those with $\epsilon_{\mathrm{org}}^{\mathrm{MC}}(\mathrm{Cy} 31 \mathrm{r} 1$ and CONV; blue and green lines), which are reduced significantly by a 10 -day forecast lead time. Therefore, Figure 7 shows that, with the modified formulation of organized entrainment, the IFS is able to maintain the eastward-propagating spectral power of the MJO at longer forecast lead times. Using a similar metric, studies have shown that a smaller-than-observed east-west ratio of MJO spectral power is a common feature among most of the CMIP3 models (Lin et al., 2006) and state-of-the-art climate models (Kim et al., 2009).

\section{Conclusions}

The hindcast experiments performed in this study present a unique opportunity to attribute changes in the simulation of the MJO in the IFS seen in B08 to individual model modifications. MJO diagnostics (Waliser et al., 2009) have been applied to the versions of the IFS described in Table 1. Although both Cy31r1 and OPER are able to reproduce the eastward-propagating, intraseasonal signal of the MJO at a 1-day forecast lead time (Figures 1 and 2), Cy31r1 underestimates the variance in OLR across the equatorial Indo-Pacific region. OPER is able to reproduce the observed variance of OLR on the intraseasonal time-scales of the MJO after a 1-day forecast lead time (Figure 3) but, 


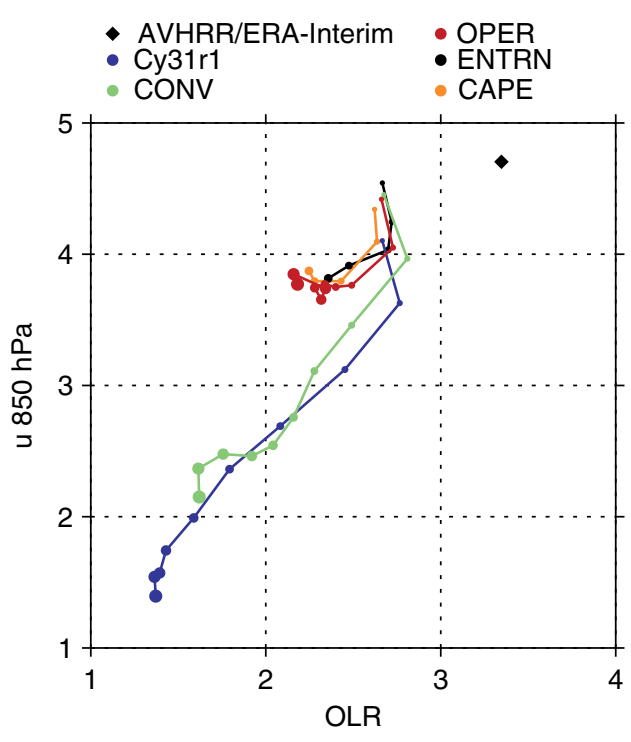

Figure 7. East-west ratio of MJO (20- to 80-day mode, within wavenumbers $1-3$ for OLR and 1-2 for zonal wind) spectral power calculated by dividing the sum of eastward-propagating power by the westward-propagating equivalent. The ratio from AVHRR OLR and ERAInterim $850 \mathrm{hPa}$ zonal wind (black diamond) is compared to all of the versions of the IFS described in Table 1. Lines (and increasing dot size) refer to increasing forecast lead time up to 5 days for CAPE and ENTRN (orange and black lines) and 10 days for Cy31r1, CONV and CAPE (blue, green and red lines).

because variance increases with increasing lead time, OPER significantly overestimates the convective variance later in the forecast. Through comparison with the hindcast experiments, it was shown that the Cy32r3 convective parametrization alone increased the predictive skill of the EOFs during the YOTC period by 3 days (Figure 5). Additionally, the Cy32r3 formulation of convection, or $\epsilon_{\mathrm{org}}^{\mathrm{RH}}$ specifically, increased the convective intraseasonal variability across the entire equatorial Indian Ocean and West Pacific Warm Pool (Figure 3). The simulation of convective variability is shown to be more sensitive to the formulation of organized entrainment than simply reducing the rate of organized entrainment. However, it is important to note that halving the rate of organized entrainment amounts to approximately a $25 \%$ reduction in total entrainment. Further reducing the total entrainment would significantly weaken the exchange of mass at cloud base which, in turn, would weaken the sensitivity to environmental air (de Rooy et al., 2012). It is also shown that changing to a variable CAPE time-scale in the closure for deep convection had minimal compensating effects. Therefore, the introduction of the Cy32r3 convective parametrization has led to an overactive MJO in the IFS; cycle 35r3 implemented in October 2009 has been shown to partially solve this problem (Vitart and Molteni, 2010).

An advantage of the NWP approach to studying the MJO is that the specific characteristics of individual events, in this case the April 2009 MJO, can be examined in model simulations and direct comparisons can be made with observational data. Consistent with the increased OLR variance, $\epsilon_{\mathrm{org}}^{\mathrm{RH}}$ increased the amplitude of the MJO in all regions. The new variable $\mathrm{CAPE}$ adjustment time-scale reduced the amplitude of the MJO in the Indian Ocean. Therefore, the combined impact of the Cy32r3 convective parametrization was to maintain the amplitude of the MJO at longer forecast lead times. Again, the simulation of the
MJO was shown to be more sensitive to the formulation of entrainment than the entrainment rate (Figure 6).

This study has shown that improvements in the simulation of the MJO in the IFS can be directly attributed to the formulation of convection in Cy32r3, specifically, the relative-humidity-dependent formulation for organized entrainment. The decision to move to a formulation for entrainment that was dependent on relative humidity was motivated by the recognition that environmental moisture is crucial in modulating the location and strength of convective activity on MJO time-scales (Redelsperger et al., 2002; Grabowski, 2003; Grabowski and Moncrieff, 2004). However, it is not just the humidity dependence of the organized deep entrainment rate which is important to the accurate simulation of cumulus convection in the IFS. de Rooy et al. (2012) conclude that, although the relative-humidity-dependent entrainment factor in the IFS is very important, it is more important that the overall entrainment constant is large. Therefore, the sensitivity to the environmental moisture in the IFS can be thought of as twofold; having strong entrainment at cloud base provides the 'first' sensitivity to the environment, while having a relative-humidity-dependent formulation for organized entrainment during the parcel ascent provides the 'second'.

While the diagnostics applied in this study, and metrics such as that in Figure 7, can highlight deficiencies in the ability of numerical models to simulate the MJO, they cannot alone provide insight into the physical mechanisms responsible. For example, with these diagnostics alone, the MJO can be fully characterized in a model but conclusions cannot be drawn about which processes are integral to its onset and evolution. This has led to the recognition that more process-based diagnostics should be applied to simulations of the MJO (e.g. Kim et al., 2009; Zhu et al., 2009). The discussion and application of such diagnostics and this mechanistic approach will be the subject of Hirons et al. (2012).

\section{Acknowledgements}

The authors would like to thank the National Environmental Research Council (NERC) for providing the PhD scholarship that made this work possible and ECMWF for their support of this work.

\section{References}

Bechtold P, Köhler M, Jung T, Doblas-Reyes F, Leutbecher M, Rodwell MJ, Vitart F, Balsamo G. 2008. Advances in simulating atmospheric variability with the ECMWF model: from synoptic to decadal timescales. Q. J. R. Meteorol. Soc. 134: 1337-1351.

Bond NA, Vecchi GA. 2003. The influence of the Madden-Julian Oscillation on precipitation in Oregon and Washington. Weather Forecast. 18: 600-613.

Dee DP, Uppala SM, Simmons AJ, Berrisford P, Poli P, Kobayashi S, Andrae U, Balmaseda MA, Balsamo G, Bauer P, Bechtold P, Beljaars ACM, van de Berg L, Bidlot J, Bormann N, Delsol C, Dragani R, Fuentes M, Geer AJ, Haimberger L, Healy SB, Hersbach H, Holm EV, Isaksen L, Kallberg P, Kohler M, Matricardi M, McNally AP, MongeSanz BM, Morcrette JJ, Park BK, Peuby C, de Rosnay P, Tavolato C, Thepaut JN, Vitart F. 2011. The ERA-Interim reanalysis: configuration and performance of the data assimilation system. Q. J. R. Meteorol. Soc. 137: 553-597.

Derbyshire SH, Beau I, Bechtold P, Grandpeix JY, Piriou JM, Redelsperger JL, Soares PMM. 2004. Sensitivity of moist convection to environmental humidity. Q. J. R. Meteorol. Soc. 130: 3055-3079. de Rooy WC, Bechtold P, Frölich K, Hohenegger C, Jonker H, Mironov D, Siebesma AP, Teixeira J, Yano JI. 2012. Entrainment and detrainment 
in cumulus convection: an overview. Q. J. R. Meteorol. Soc., DOI: 10.1002/qj.1959

Grabowski WW. 2003. MJO-like coherent structures: sensitivity simulations using the cloud-resolving convection parameterization (CRCP). J. Atmos. Sci. 60: 847-864.

Grabowski WW, Moncrieff MW. 2004. Moisture-convection feedback in the tropics. Q. J. R. Meteorol. Soc. 130: 3081-3104.

Hendon HH, Liebmann B. 1990. The intraseasonal (30-50 day) oscillation of the Australian Summer Monsoon. J. Atmos. Sci. 47: 2909-2923.

Hirons LC, Inness P, Vitart F, Bechtold P. 2012. Understanding advances in the simulation of intraseasonal variability in the ECMWF model. Part II. The application of process-based diagnostics. Q. J. R. Meteorol. Soc., DOI: 10.1002/qj.2059.

Inness PM, Slingo JM. 2006. The Interaction of the Madden-Julian Oscillation with the Maritime Continent in a GCM. Q. J. R. Meteorol. Soc. 132: 1645-1667.

Kessler WS, McPhaden MJ. 1995. Forcing of intraseasonal Kelvin waves in the equatorial Pacific. J. Geophys. Res. 100: 10613-10631.

Kim D, Sperber K, Stern W, Waliser D, Kang I-S, Maloney E, Wang W, Weickmann K, Benedict J, Khairoutdinov M, Lee M-I, Neale R, Suarez M, Thayer-Calder K, Zhang G. 2009. Application of MJO simulation diagnostics to climate models. J. Climate 22: 6413-6436.

Lawrence DM, Webster PJ. 2002. The Boreal Summer Intraseasonal Oscillation: relationship between northward and eastward movement of convection. J. Atmos. Sci. 59: 1593-1606.

Liebmann B, Smith CA. 1996. Description of a complete (interpolated) OLR dataset. Bull. Am. Meteorol. Soc. 77: 1275-1277.

Lin JL, Kiladis GN, Mapes BE, Weickmann KM, Sperber KR, Lin W, Wheeler MC, Schubert SD, Genio AD, Donner LJ, Emori S, Gueremy JF, Hourdin F, Rasch PJ, Roeckner E, Scinocca JF. 2006. Tropical intraseasonal variability in 14 IPCC AR4 climate models. Part I. Convective signals. J. Climate 19: 2665-2690.

Madden RA, Julian PR. 1971. Detection of a 40-50 day oscillation in the zonal wind in the tropical Pacific. J. Atmos. Sci. 28: 702-708.

Maloney ED, Hartmann DL. 2000. Modulation of eastern North Pacific hurricanes by the Madden-Julian Oscillation. J. Climate 13: $1451-1460$.

Matthews AJ. 2004. Intraseasonal variability over tropical Africa during northern summer. J. Climate 17: 2427-2440.

Mo KC. 2000. Intraseasonal modulation of summer precipitation over North America. Mon. Weather Rev. 128: 1490-1505.

Morcrette JJ, Barker HW, Iacono MJ, Mozdzynski G, Pincus R,
Salmond D, Serrar S. 2007. A new radiation package McRAD. ECMWF Newsl. 112: 22-32.

Nakazawa T. 1988. Tropical super clusters within intraseasonal variations over the western Pacific. J. Meteorol. Soc. Japan 66: 823-839.

Redelsperger JL, Parsons DB, Guichard F. 2002. Recovery processes and factors limiting cloud-top height following the arrival of a dry intrusion observed during TOGA-COARE. J. Atmos. Sci. 59: 2438-2457.

Salby ML, Garcia RR, Hendon HH. 1994. Planetary-scale circulations in the presence of climatological and wave-induced heating. J. Atmos. Sci. 51: 2344-2367.

Slingo JM, Sperber KR, Boyle JS, Ceron JP, Dix M, Dugas B, Ebisuzaki W, Fyfe J, Gregory D, Gueremy JF, Hack J, Harzallah A, Inness P, Kitoh A, Lau WKM, McAvaney B, Madden RA, Matthews AJ, Palmer TN, Park CK, Randall DA, Renno N. 1996. Intraseasonal oscillations in 15 atmospheric general circulation models: results from an AMIP diagnostic subproject. Clim. Dynam. 12: 325-357.

Vitart F. 2003. 'Monthly forecasting system'. Technical Report 424, ECMWF, Reading, UK.

Vitart F, Molteni F. 2010. Simulation of the MJO and its teleconnections in the ECMWF forecast system. Q. J. R. Meteorol. Soc. 136: 842-855.

Vitart F, Woolnough SJ, Balmaseda MA, Tompkins AM. 2007. Monthly forecast of the Madden-Julian Oscillation using a coupled GCM. Mon. Weather Rev. 135: 2700-2715.

Waliser DE, Sperber KR, Hendon HH, Kim D, Maloney ED, Wheeler MC, Weickmann KM, Zhang C, Donner L, Gottschalck J, Higgins W, Kang IS, Legler D, Moncrieff M, Schubert S, Stern W, Vitart F, Wang B, Wang W, Woolnough SJ. 2009. MJO simulation diagnostics. J. Climate 22: 3006-3030.

Wheeler MC, Hendon HH. 2004. An all-seasonal real-time multivariate MJO index: development of an index for monitoring and prediction. Mon. Weather Rev. 132: 1917-1932.

Woolnough SJ, Vitart F, Balmaseda MA. 2007. The role of the ocean in the Madden-Julian Oscillation: implications for MJO prediction. Q. J. R. Meteorol. Soc. 133: 117-128.

Zhang C. 2005. Madden-Julian Oscillation. Rev. Geophys. 43: RG2003, DOI: $10.1029 / 2004 R G 000158$.

Zhang C, Dong M, Gualdi S, Hendon HH, Maloney ED, Marshall A, Sperber KR, Wang W. 2006. Simulations of the Madden-Julian Oscillation in four pairs of coupled and uncoupled global models. Clim. Dynam. 27: 573-592.

Zhu H, Hendon HH, Jakob C. 2009. Convection in a parameterized and superparameterized model and its role in the representation of the MJO. J. Atmos. Sci. 66: 2796-2811. 